\section{Birlesik Dünya Arastrma Cypriot Journal of Educational \\ Sciences}

Volume 16, Issue 3, (2021) 939-951
CWES

www.cjes.eu

\title{
Developing a heutagogy approach to promoting teacher competencies in Indonesia
}

Silvia Mariah Handayani ${ }^{\text {* }}$, Southern Cross University, School of Education, Military Road, East Lismore NSW 2480, Australia. https://orcid.org/0000-0002-9558-5114.

Tony Yeigh ${ }^{\text {b }}$, Southern Cross University, School of Education, Military Road, East Lismore NSW 2480, Australia. https://orcid.org/0000-0002-8795-8515.

Lisa Jacka ', Southern Cross University, School of Education, Southern Cross Drive, Bilinga QLD 4225, Australia https://orcid.org/0000-0002-1389-8978.

Lewes Peddell d, Southern Cross University, School of Education, Southern Cross Drive, Bilinga QLD 4225, Australia. https://orcid.org/0000-0001-8947-877X.

\section{Suggested Citation:}

Handayani, S.M., Yeigh, T., Jacka, L., \& Peddell, L. (2021). Developing a heutagogy approach to promoting teacher competencies in Indonesia. Cypriot Journal of Educational Science. 16(3), 939-951. https://doi.org/10.18844/cjes.v16i3.5765

Received from December 05, 2020; revised from February 10, 2021; accepted from May 20, 2021.

(C2021 Birlesik Dunya Yenilik Arastirma ve Yayincilik Merkezi. All rights reserved.

\section{Abstract}

This study aims to establish a Heutagogy approach for teacher professional education in Indonesia as an attempt to improve teacher competencies. This study will identify key elements of a Heutagogy approach derived from previous Heutagogy practices. The methods to collect data for developing the Heutagogy approach in this study employs a literature review of previous research and findings related to Heutagogy practice. In this regard, this study's established elements are Learnerdetermined learning, Metacognitive reflection, Collaboration, and Capability development. These elements are analysed and then incorporated into the TPE model with support from online learning tools. Capability development is the goal of experiencing each of the elements of Heutagogy in this approach. Each of these key elements will contribute to developing participants capability as professional teachers. The Heutagogy approach in this study is expected to be significant for improving teacher competencies in Indonesia.

Keywords: teacher professional education, heutagogy

\footnotetext{
* ADDRESS FOR CORRESPONDENCE: Silvia, Handayani, Southern Cross University, Military Road East Lismore NSW 2480, Australia E-mail address: s.handayani.10@student.scu.edu.au / Tel.: +061-2-6620-300
} 


\section{Introduction}

Indonesia is a developing country located in South-East Asia facing several obstacles related to education quality, including teaching effectiveness (De Ree, Muralidharan, Pradhan, \& Rogers, 2015). Based on The World Bank (2003) research, Indonesian teachers, in general, demonstrate insufficient competency due to relatively inadequate levels of primary education and relatively few opportunities for systematic in-service training. Therefore the Indonesian government established Teacher Professional Education (TPE) in 2005 to improve teaching quality (Kusumawardhani, 2017). The objective of the program is to provide new teachers with competence in planning, implementing, and assessing learning and conducting research and developing professionalism (Ministry of Education and Culture, 2013). In the final phase of the program, teachers will obtain certificates of professionalism as a teacher.

Since its establishment in 2005, the TPE began to enrol Indonesia in 2007 . Teachers have been selected to attend the TPE in several cohorts. However, upon completing the training, the National Competency test results for teachers in Indonesia indicate that teacher competency is insufficient. The analysis revealed that teacher training is not working effectively to improve teacher competencies and capabilities. In this respect, the average result of the Indonesian National Teacher Competency Test in 2012 indicated that teacher competency was below standard. Teachers were expected to score at least 70, however, the average score was only 42 (scale 0-100, cf. Kusumawardhani, 2017; Prihono, 2014; Rahman, Abdurrahman, Kadaryanto, \& Rusminto, 2015). Moreover, in general, Indonesian teachers demonstrated insufficient competence concerning the mastery of subject matter, which was viewed as due to relatively low primary education levels coupled with relatively few opportunities for systematic in-service training (Chang et al., 2013).

As a result, in 2019, the Indonesian Education Minister provided more training for instructors and TPE participants before program commencement. The content of the program was also upgraded based on the need of the participants (Murdiyanto, 2020). Later in 2020, due to the COVID 19 pandemic, the Indonesian education authorities authorised that all learning mode at all levels shifted to online learning (Ministry of Education and Culture of Indonesia, 2020). The government established Act No 4 in 2020 regarding learning activities in response to the COVID 19 pandemic. This policy has been in place since March 2020 to maintain physical distancing as an attempt to stop the spreading of the virus in Indonesia. Based on this instruction, the overall learning in TPE is now conducted online.

Currently, TPE in Indonesia continues evolving to discover a compatible strategy to promote learning outcomes. Therefore in this study, a heutagogy approach has been adopted to support TPE in Indonesia. The effectiveness lies in the principles of a heutagogy approach which aims to correspond to the problems that occur during learning, aiming to prepare educators who can implement a new education approach based on a lifelong learning ideal that canvasses the life cycle, including formal, nonformal, and informal education and training (Leach \& Moon, 2000; The World Bank, 2003). In this respect, Heutagogy has emerged as one of the approaches that facilitate learning combined with technological advancement. A heutagogy practice engages the World Wide Web to accommodate learners sharing ideas, working together, and reflecting on previous learning. Heutagogy also facilitates learners to develop full capability. Capable learners can implement competencies developed through education in different workplace types and constantly changing situations (Hase \& Davis, 1999). Thus the application of heutagogy to the Indonesian TPE appears relevant, timely and logical.

This study aims to establish a TPE approach based on heutagogy to improve teacher engagement and teacher competencies for TPE in Indonesia. This study will identify key elements of a Heutagogy 
approach derived from the knowledge and information obtained from previous heutagogy practices. The heutagogy approach for TPE will facilitate training teachers to improve overall competencies. Heutagogy also allows teachers to evaluate their performance, contributing to individual up-skilling overall. With heutagogy, these learners will have opportunities to interact with different learning resources and develop individual training outcomes based on personal interests and talents.

\section{Methods and Materials}

\subsection{Heutagogy Approach}

Hase and Kenyon (2013) proposed Heutagogy as an ideal approach to learning in the $21^{\text {st }}$ century, emphasising capability development. Heutagogy uses personal experience to develop capability. Hase and Kenyon were the first scholars who introduced heutagogy to advance pedagogy and andragogy (Hase \& Kenyon, 2000; 2003; 2007). The term Heutagogy is adapted from the ancient Greek "heutos", meaning "self", and "agogy" meaning "learning" (Hase \& Kenyon, 2007, p.112). Heutagogy can be taken to mean "self-learning", or as defined by Hase and Kenyon, as the study where learners determined their learning way (Hase \& Kenyon, 2007; 2000; 2003). An essential distinction of Heutagogy is that learners are at the centre of the learning, whereas teachers are tasked to provide learning resources and act as facilitators to guide the learning (Blaschke, Kenyon \& Hase, 2014; Eberlee, 2009; Hase \& Kenyon, 2000).

The main idea in Heutagogy is the transfer of control from teacher to learner (Blaschke, 2016; Blaschke, Kenyon \& Hase, 2014), wherein learners serve as the "architects" of their own learning experience (Snowden \& Halsall, 2016, p.7). In Heutagogy, a learner is given the space to determine the learning objective based on their interests and needs. The learner also allowed to design the learning strategy to support the learner to achieve the learning objective (Wehmeyer et al., 2012). Selfdetermined learning can increase learner involvement in learning because there is the freedom to manage behaviour by enhancing instruction, monitoring, and evaluation (Wehmeyer et al., 2017).

\subsection{Elements of a Heutagogy Approach}

An essential distinction of Heutagogy is placing the learner at the centre of the learning process, whereas teachers are tasked to provide learning resources as well as act as facilitators to guide the learning process (Blaschke, Kenyon \& Hase, 2014; Hase \& Kenyon, 2000). As a teaching and learning construct, the underlying, conceptual components of Heutagogy are learner determined learning, metacognitive reflection, collaboration, and capability development (Ashton \& Newman, 2006, Ashton \& Elliot, 2007; Blaschke, 2012; Canning, 2010, Canning \& Callan, 2010; Hase \& Kenyon, 2000; 2013). Understanding each of these components and how each interact to support overall Heutagogy learning will help develop the Heutagogy approach for TPE in Indonesia. 


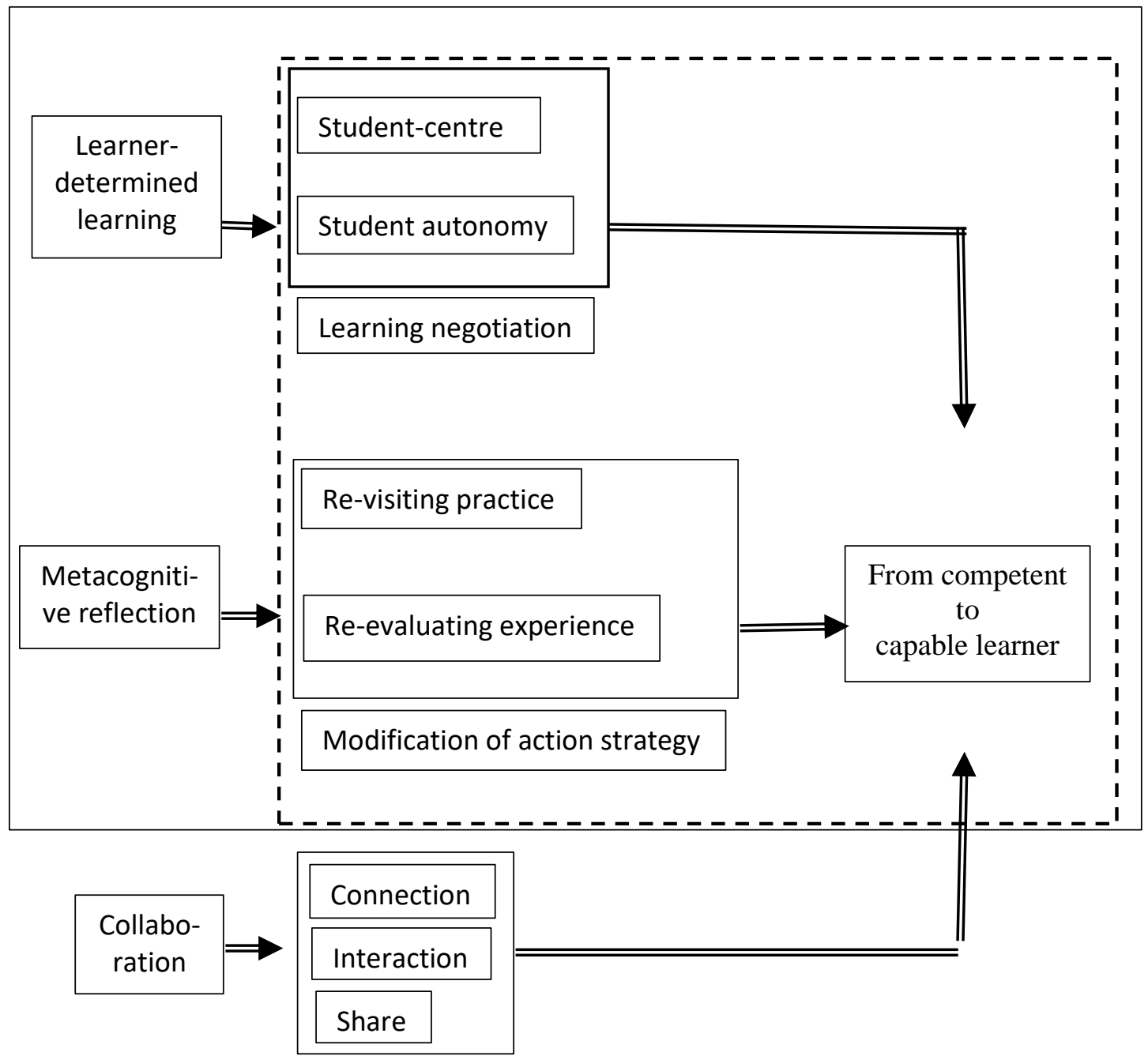

Figure 1. Elements of a Heutagogy approach

Blaschke (2016) claimed Heutagogy as the continuation of preceding theories that emerge from the current digital society. Digitally-influenced learning in these times promotes students to self-direct a pursuit of knowledge with limited teacher assistance. This proposes a shift in teaching and learning instruction is required by involving technology that supports a teacher to be innovative and creative in designing student-centred learning (Kenyon \& Hase, 2001). The combination of technology in a Heutagogy approach allows learners with the opportunity to be actively involved in learning, enhancing creative thinking (McLoughlin \& Lee, 2007; Blaschke, 2014). Online media in Heutagogy is utilised to facilitate collaboration and reflection in learning that stimulates teachers to create new knowledge and promote initiatives (Sari, 2012, p.71). 
In this investigation, all elements of a Heutagogy approach are facilitated by online media. Canning (2010) suggests that online forums such as social networking can promote Heutagogy learning. In online settings, learners are allowed to share information and problems. This experience can help learners establish new knowledge without being overwhelmed by learning assessment (Canning, 2010). Moreover, Blaschke (2013) argues that technology supports the implementation of Heutagogy learning. By utilising technology, students benefit from discovering and producing individualised learning content, building learning communities, and re-evaluating current knowledge to create new learning pathways (Blaschke, 2013).

\subsection{Methodology}

The Heutagogy utilised in this study is derived from an in-depth review of theories and research results of Heutagogy practice. In this regard, the elements of a Heutagogy have been established from current and past educational practice on Heutagogy, with an emphasis on Heutagogy practice in teacher education. These elements are analysed in the context of TPE in Indonesia. The selected elements have been then incorporated into a TPE model with support from online learning tools.

\section{Results and Discussion}

\subsection{Learner-determined Learning}

The main idea in learner-determined learning is the transfer of control from teacher to learner (Blaschke, 2016; Blaschke, Kenyon \& Hase, 2014). Canning and Callan (2010) suggest that learners can benefit from learner-determined learning by empowering themselves via the creation of knowledge, discovering personal learning strategies, building confidence by actively participating in learning, and learning to communicate thoughts and ideas of the subject in question. In this regard, Hase and Kenyon (2013) note that the shifting the paradigm in learning, driven by the knowledge economy and responded to by Heutagogy, generates learning experiences, encourages ideas and reinforces the learner's motivation to re-examine previous learning (Hase \& Kenyon, 2003). Learner-determined learning thus represents a highly student-centred learning approach, and in this respect, Kerry (2013) found that when applying the principles of Heutagogy, teachers act as facilitators and mentors for learners however continuing to evaluate the needs of the learners through this approach. Accordingly, Brandt's (2013) study on perspectives towards Heutagogy implies that "teachers are the foundational control in the classroom that encourage, support, inspire, and provide feedback as well as serving as the source of learning" (p.110).

Blaschke and Hase (2016) propose six design elements of learner-determined learning: "explore, create, collaborate, connect, reflect, and share" (p.32). First, "exploration" is considered important as learners need the freedom to explore different kinds of knowledge. Through exploration, learners will be encouraged to establish a personal hypothesis and then test it and ask and answer questions regarding the associated learning process. Second, "creating" multiple learning approaches through written expression or ideas is also crucial in learner-determined learning. Next, "collaboration" is necessary to create an environment where learners can explore learning with and from peers. Afterwards, "connecting" and "sharing" also play a significant role as Heutagogic design principles. By connecting with different people worldwide, a learner gains opportunities to share information and knowledge and discover new ideas related to personal learning improvement. Finally, "reflection" gives learners productive time to develop ideas cognitively by analysing and synthesising previous and current learning. 
Learner determined learning has become one of the key elements in a TPE Heutagogy approach because the participant needs to determine what and how they need to learn to develop competency as a teacher. This learner determined learning can direct participants to seek other learning resources in finding information and solutions related to individual teaching capabilities. The abundance of learning resources will stimulate participants to analyse information that corresponds to learning needs and finally select the information required to enrich personal knowledge.

\subsection{Metacognitive Reflection}

The Metacognitive Reflection process in Heutagogy is described as a "double-loop learning" that defines a process to detect and correct errors (Argyris, 2002). Double-loop learning takes place when governing values and actions are modified to correct errors. In Double-loop learning, learners study the process of their own thinking until a conclusion is reached, followed by considering how thoughts shifted to find the best solutions to address a problem (Eberlee, 2009). Blaschke (2012) notes that in Doubleloop learning, "learners consider the problem and the resulting action and outcomes, in addition to reflecting upon the problem-solving process and how it influences the learner's own beliefs and actions" (p. 59). From here, Metacognition and Reflection can be seen to hold an important role in a Heutagogy approach.

Reflective Practice emerges from teacher reflection on abstract or concrete issues based on individual practice in a teacher education context. Collin, Karsenti, and Komis (2013) summarise the meaning of Reflective Process in the context of teacher education as:

...a process (examining, thinking and understanding, problem-solving, analysing, evaluating and/or constructing, developing and transforming) concerning a particular object (practice, social knowledge, experience, information, theories, meaning, beliefs, self and/or issues of concern) and in view of achieving a particular goal, or rationale (think differently or more clearly, justify one's stance, think about actions or decisions, change thinking or knowledge, take or improve action, improve student learning, alter self or society) (p.105).

Considering a Metacognitive reflection for teacher education in more detail, Peeters and Robinson (2015) assert that the Reflective Process is a way of correcting mistakes to promote teachers developing personal competencies. Here, Peeters and Robinson (2015) interpret mistakes as "a mismatch between desired and actual outcomes" (p.214). Therefore, proposing that "Single" and "Double-loop" learning arises as a means of correcting mistakes. Single-loop learning occurs if a mistake is corrected simply by modifying the action strategies, questioning the actions' effectiveness, without, however, questioning the reasons for choosing those actions. Conversely, if a mistake is corrected through action that causes modification of assumptions and beliefs, this is where Double-loop learning ensues.

In the context of TPE, Metacognitive reflection is chosen as key elements of a Heutagogy approach as participants need to reflect on individual past and current teaching practice. Reflection will allow participants to locate mistakes and then correct them by experiencing the knowledge and information obtained through TPE. Sharing Reflective Practice with colleagues will provide more insight into improving personal teaching capabilities.

\subsection{Collaboration}

Collaboration in learning also contributes to Heutagogic learning success (Blaschke, 2012; Blaschke \& Hase, 2016; Canning \& Callan, 2010). Dick (2013) suggests that information is shared and passed 
representing individual learner understanding when learners work together. Then, as learners visualise colleagues' experiences as a reality, a desire to collaborate and solve problems increases. Canning and Callan (2010) assert that when learners are engaged in collaborative learning, the partners are involved in a learning environment where to provide information and share it exists naturally. As a result, learners can solve their problems and strengthen knowledge by exchanging valuable information and experimenting to determine which practice corresponds to their experience (Blaschke \& Hase, 2016).

Relevant to the TPE, a Heutagogy approach designed in this study includes collaboration as one of the key elements as sharing information can enrich knowledge as well as provide opportunities to connect and collaborate with other colleagues who experience similar or differing issues in teaching. Collaboration can benefit participants in exploring information and establishing new ideas in anticipating possible difficulties in teaching and learning activities.

\subsection{Competent to Capable}

Competency and Capability are two essential constructs that lie within Heutagogy (Hase \& Kenyon, 2013; McAuliffe, Hargreaves, Winter, \& Chadwick, 2009). According to Snowden and Halsall (2014), Heutagogy highlights capability development within the context of life-long learning as it presents an approach that utilises learner-determined learning. Hase and Davis (1999) refer to 'competency' as the mastery of "knowledge and skills" (p.2). As for Capability, Hase and Davis (1999) refer to capable people as "those who: know how to learn; are creative; have a high degree of self-efficacy; can apply competencies in the novel as well as familiar situations; and work well with others" (p.2). Similar to Hase and Davis (1999), Stephenson (1998) defines capability as "an integration of knowledge, skills, personal qualities and understanding used appropriately and effectively - not just in familiar and highly focused specialist contexts but in response to new and changing circumstances" (p.2).

In this regard, the characteristics of 'capable' people are to possess a high level of self-efficacy, being able to communicate and work effectively within a group, being able to respond creatively to unfamiliar situations, able to be adaptable as well as flexible, and possessing positive values (Hase \& Kenyon, 2000; Gardner, Hase, Gardner, Dunn \& Carryer, 2008). When applied to a Heutagogical approach, this suggests that' competency' and 'capability' will always attach and support each other to achieve the goal of learning from a learner-determined perspective.

The Heutagogy approach in this study placed 'capability' development as the goal of the outlined learner-determined learning, metacognitive reflection, and collaboration. Each of these key elements will contribute to developing participants capability. Overall, Heutagogy learning activities in this approach are designed to facilitate TPE participants to improve competencies and implement these competencies in different education settings.

\subsection{Embedding elements of Heutagogy into TPE}

In general, the learning process in TPE consists of pedagogical content, developing teaching aids, peer-teaching, and field experience (Ministry of Research, Technology and Higher Education, 2018). The Heutagogy approach is designed online in response to the COVID 19 restrictions in Indonesia. Below is a description of the overall learning activities in the Heutagogy approach designed for TPE. 


\section{Pre-test}

The pre-test takes place before the learning begins to measure the initial competencies of the participants. The test consists of 50 multiple choice questions delivered via Qualtrics. The participants will be given 50 minutes to complete the test.

\section{Workshops}

The first activity in the workshops is the facilitator delivering information about the implementation of the training. Then, the facilitator will introduce online media and present instructions about how to use online media during the learning process. During this phase, participants provide personal previous teaching portfolios to be assessed in a group. Afterwards, the facilitator divides the participants into several small groups consisting of 4-5 people using stratified sampling. In this respect, the small group participants are selected based on the region of home-based institutions. Those who come from the same area are not to stay in the same group. The aim is to have the participants share different problems and different policies related to individual institutions.

\section{Learning in a network}

At the beginning of the learning, participants are asked to read the training modules in Google Classroom. Participants are free to choose topics of interest based on difficulties in teaching. This first task leads participants to learner-determined learning. Within each small group, the participants will discuss the teaching documents based on individual experiences. Each individual is required to give feedback on every document. Later, each group representative will upload the group discussion to the provided space on Google Classroom. Afterwards, other groups will give comments and suggestions. In this process, the students are directed into Metacognitive Reflection and Collaboration. As a result, each group will revise their teaching documents based on the findings from their discussions. Participants benefit from detecting errors in practice from these activities, resulting in alteration in plans, strategies, and beliefs. These experiences will also encourage students to identify any issues or drawbacks critically, within personal teaching practice. Collaboration at this stage will allow participants to share ideas and information to contribute to knowledge enrichment.

\section{Peer teaching}

Teaching documents from previous collaborative activities will be the official documents for participants during the peer teaching session. Participants will benefit from Capability Development based on findings generated in this peer teaching session. The peer teaching session is organised via Zoom Meeting. The participants will demonstrate new teaching practice consecutively, and the other participants will become the audience. Participants will be encouraged to give feedback and suggestions to colleagues.

\section{Field experience}

At this stage, the TPE committee will distribute the participants into several locations to practice teaching. The duration of the field experience is two weeks. The participants will communicate with the selected school and mentor teacher. The participants choose one session to broadcast in a Zoom Meeting session. In this session, the facilitator and mentor teacher can give feedback and evaluate performance. This activity will require participants to employ Learner-determined learning on planning the teaching practice. Hereafter, the field practice will also develop the participant's capability by demonstrating individual knowledge and benefiting from the facilitator and mentor teacher. 


\section{Seminar and discussion}

In these sessions, each group will present experiences related to field practice to other groups. Facilitators and other groups will provide feedback based on the documents created and discussed during the training. Further, each individual will write a progress report in Google Classroom. The participants will also explain the obstacles experienced during the learning process and how these will assist in anticipated similar barriers in future teaching episodes. Moreover, here, a Metacognitive Reflection process will assist participants in evaluating their teaching performance.

\section{Post-test}

The participants will complete a post-test at the end of the program. The aim is to see whether there is an increase of competencies via the use of this Heutagogy approach before and after the training. The pre and post-test scores will be compared to measure the effectiveness of learning within this Heutagogy approach. Figure 2 below presents the Heutagogy TPE approach designed in this study.

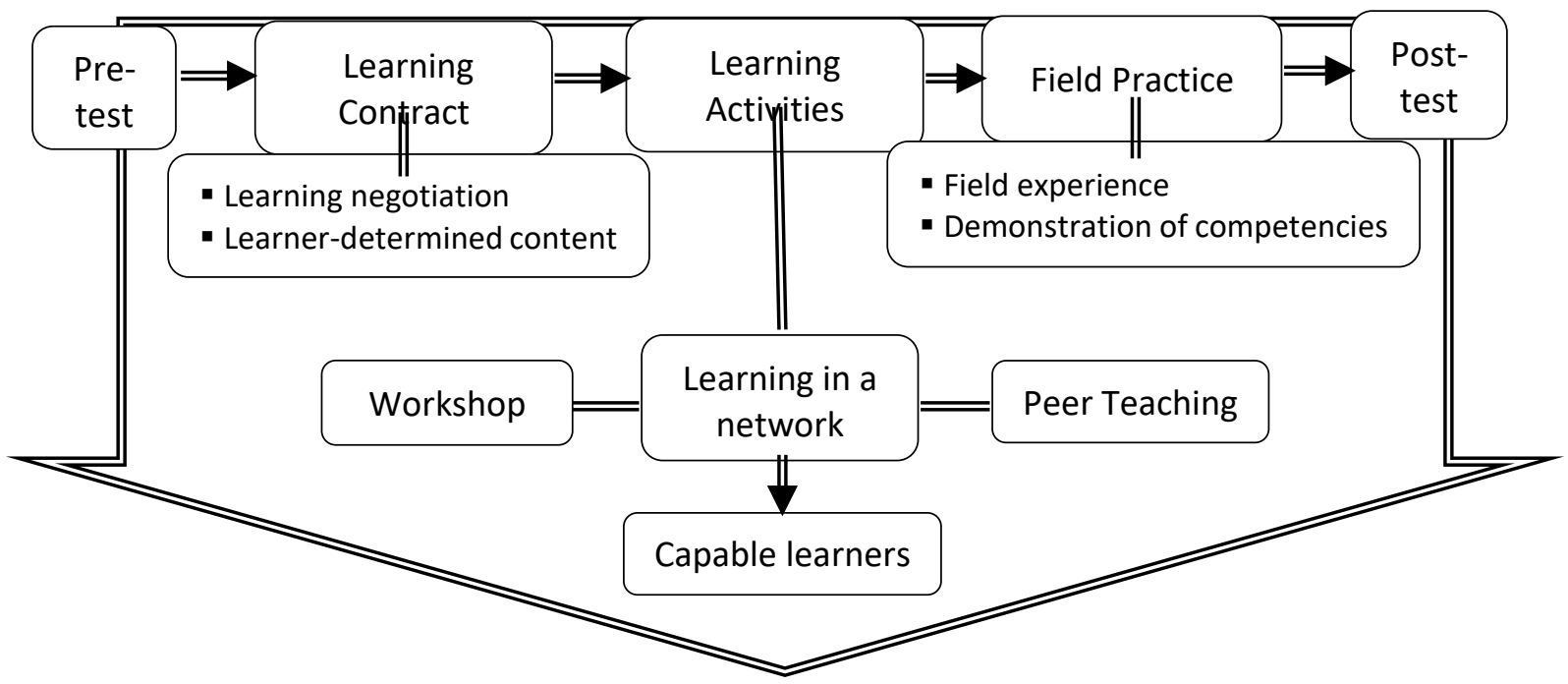

Figure 2. The Heutagogy approach proposed for TPE

The Heutagogy approach designed in this study encourages participants to engage in learning via Google Classroom, allowing participants to review and provide comments and suggestions on colleagues using a reflective worksheet. A study by Bedenlier et al. (2020) found that online media that provide a space for discussion can stimulate learners by alleviating anxiety in participants to create responses and encourage participants to contribute to the learning. Kahu and Nelson (2018) emphasise that engaging student in learning is the key factor in achieving successful learning. One way to enhance learners engagement is by applying educational technology such as online learning tools (Bedenlier et al., 2020). Educational technology facilitates learners with intensive learning that stimulates participants to actively participate in learning (Bond et al., 2020). However, learners and teachers must understand the reason for using the selected learning tools, and it may require more time for each of them to learn to utilise the tools (Bedenlier et al., 2020).

\section{Conclusion and Recommendations}

Based on this literature review, four main principles lie within the Heutagogy approach: Learnerdetermined learning, Metacognitive reflection, Collaboration, and Capability development. The 
objective of learning in Heutagogy settings is to promote learners to develop capability from individual competencies. The Heutagogy approach in this study is designed for learning activities during the COVID 19 pandemic. Therefore, to maintain social distance among the participants, the approach embeds online media to facilitate the learning process. In this regard, online media appears to correspond with the elements of Heutagogy that promote the participants into a learner-determined learning environment.

The concept of Heutagogy indeed has some challenges in implementation. Barriers might come from the learners, learning organisations, the interaction between learners and teachers, and the teaching role during the learning process. Related to the learners, the feelings of "incompetent and insecure" might arise when learners are asked to take responsibility for determining individual learning goals (Van Woezik, Reuzel \& Koksma, 2019, p.4). Hence, teachers in Heutagogy must ensure that learners understand the learning objective and utilise these as a reference in learning activities. Moreover, teachers must fully understand the role of the facilitator of learning. Of importance, teachers must possess the ability to guide the learning while allowing for 'democracy' for learners to self-determined the learning.

An empirical result about the implementation of Heutagogy is very limited. Therefore, for further research, there is a need for more quantitative data about the critical elements of Heutagogy, such as "capability development and non-linearity" (Agonács \& Matos, 2019, p.13). Moore (2020) argued although Heutagogy provides opportunities to integrate the worldwide web into learning, particularly in the current Pandemic conditions, challenges will arise from institutional policies across education levels, the implementation of learning, and accreditation. Hence, Moore (2020) suggests that more empirical-based research is required to position Heutagogy as a valid learning approach.

\section{References}

Agonács, N., \& Matos, J. F. (2019). Heutagogy and self-determined learning: a review of the published literature on the application and implementation of the theory. Open Learning: The Journal of Open, Distance and eLearning, 1-18. doi:10.1080/02680513.2018.1562329

Argyris, C. (2002). Double-loop learning, teaching, and research. Academy of Management Learning \& Education, $1(2), 206-218$.

Ashton, J., \& Newman, L. (2006). An unfinished symphony: 21 st century teacher education using knowledge creating heutagogies. British Journal of Educational Technology, 37(6), 825-840. doi:10.1111/j.14678535.2006.00662.x

Ashton, J., \& Elliott, R. (2007). Juggling the balls - study, work, family and play: student perspectives on flexible and blended heutagogy. European Early Childhood Education Research Journal, 15(2), 167-181. doi:10.1080/13502930701321378

Bedenlier, S., Bond, M., Buntins, K., Zawacki-Richter, O., \& Kerres, M. (2020). Facilitating student engagement through educational technology in higher education: A systematic review in the field of arts and humanities. Australasian Journal of Educational Technology, 126-150.

Blaschke, L. M. (2012). Heutagogy and lifelong learning: a review of heutagogical practice and self-determined learning. International Review of Research in Open and Distance Learning, 13(1), 56-71. doi:10.19173/irrodl.v13i1.1076 
Blaschke, L.M. (2013). E-learning and self-determined learning skills. In Hase, S., \& Kenyon, C. (Ed.). Self-determined learning: heutagogy in action. London: Bloomsbury Publishing.

Blaschke, L. M. (2014). Using social media to engage and develop the online learner in self-determined learning. Research in Learning Technology, 22(1). doi:10.3402/rlt.v22.21635

Blaschke, L. M., Kenyon, C., \& Hase, S. (2014). Experiences in self-determined learning. Center for Open Education Research (COER), University of Oldenburg: Oldenburg, Germany. https://uol. de/fileadmin/user_upload/coer/Experiences-in-self-determined-learning. pdf.

Blaschke, L. M., \& Hase, S. (2016). Heutagogy: a holistic framework for creating twenty-first-century selfdetermined learners. In The future of ubiquitous learning (pp. 25-40): Springer.

Brandt, Barbara, A. (2013). The learner's perspective. In Hase, S., \& Kenyon, C. (Ed.). Self-determined learning: heutagogy in action. London: Bloomsbury Publishing.

Bond, M., Buntins, K., Bedenlier, S., Zawacki-Richter, O., \& Kerres, M. (2020). Mapping research in student engagement and educational technology in higher education: A systematic evidence map. International Journal of Educational Technology in Higher Education, 17(1), 2.

Canning, N. (2010). Playing with heutagogy: exploring strategies to empower mature learners in higher education. Journal of Further and Higher Education, 34(1), 59-71. doi:10.1080/03098770903477102

Canning, N., \& Callan, S. (2010). Heutagogy: spirals of reflection to empower learners in higher education. Reflective Practice, 11(1), 71-82. doi:10.1080/14623940903500069

Chang, M. C., Shaeffer, S., Al-Samarrai, S., Ragatz, A. B., De Ree, J., \& Stevenson, R. (2013). Teacher reform in Indonesia: the role of politics and evidence in policy making: The World Bank.

Collin, S., Karsenti, T., \& Komis, V. (2013). Reflective practice in initial teacher training: critiques and perspectives. Reflective Practice, 14(1), 104-117. doi:10.1080/14623943.2012.732935

De Ree, J., Muralidharan, K., Pradhan, M., \& Rogers, H. (2015). Double for nothing? Experimental evidence on the impact of an unconditional teacher salary increase on student performance in Indonesia (No. w21806). National Bureau of Economic Research.

Dick, B. (2013). Crafting Learner-Centred Processes Using Action Research and Action Learning. In Hase, S., \& Kenyon, C. (Ed.). Self-determined learning: heutagogy in action. London: Bloomsbury Publishing.

Eberle, J. (2009). Heutagogy: What your mother didn't tell you about pedagogy and the conceptual age. Paper presented at the Proceedings from the 8th annual European conference on e-learning.

Gardner, A., Hase, S., Gardner, G., Dunn, S. V., \& Carryer, J. (2008). From competence to capability: a study of nurse practitioners in clinical practice. Journal of Clinical Nursing, 17(2), 250-258. doi:10.1111/j.13652702.2006.01880.x

Hase, S., \& Davis, L. (1999). From competence to capability: The implications for human resource development and management. Graduate College of Management Papers, 163.

Hase, S., \& Kenyon, C. (2000). From andragogy to heutagogy. Ulti-BASE In-Site, 5 (3).

Hase, S., \& Kenyon, C. (2003). Heutagogy and developing capable people and capable workplaces: strategies for dealing with complexity. In Proceedings of The Changing Face of Work and Learning Conference. Edmonton, $A B$ : University of Alberta.

Hase, S., \& Kenyon, C. (2007). Heutagogy: A child of complexity theory. Complicity: An international journal of complexity and education, 4(1), 111-118.

Hase, S., \& Kenyon, C. (2013). Self-determined learning: heutagogy in action. London: Bloomsbury Publishing. 
Kahu, E. R., \& Nelson, K. (2018). Student engagement in the educational interface: understanding the mechanisms of student success. Higher Education Research \& Development, 37(1), 58-71.

Kenyon, C., \& Hase, S. (2001). Moving from andragogy to heutagogy in vocational education. Proceedings of the $4^{\text {th }}$ annual conference of Australian vocational education and training research association.

Kerry, Trevor. (2013). Applying the principles of heutagogy to a postgraduate distance-learning programme. In Hase, S., \& Kenyon, C. (Ed.). Self-determined learning: heutagogy in action. London: Bloomsbury Publishing.

Kusumawardhani, P. N. (2017). Does teacher certification program lead to better quality teachers? Evidence from Indonesia. Education Economics, 25(6), 590-618. doi:10.1080/09645292.2017.1329405

Leach, J. \& Moon, B. (2000). Changing paradigms in teacher education, a case study of innovation and change. In A. Scott \& J. Freeman-Moir (Eds). Tomorrow's teachers, international critical perspectives on teacher education (p. 83). Christchurch, New Zealand: Canterbury University Press.

McAuliffe, M., Hargreaves, D., Winter, A., \& Chadwick, G. (2009). Does pedagogy still rule? Australasian Journal of Engineering Education, 15(1), 13-18.

McLoughlin, C., \& Lee, M. (2007). Social software and participatory learning: Pedagogical choices with technology affordances in the Web 2.0 era.

Ministry of Education and Culture of Indonesia. 2013. Peraturan Pendidikan Profesi Guru Pra-jabatan No.87. Jakarta: Kementerian Pendidikan dan Kebudayaan.

Ministry of Education and Culture of Indonesia. 2020. Surat Edaran Nomor 4 tentang Pelaksanaan Kebijakan Pendidikan dalam Masa Darurat Penyebaran Corovirus Disease (COVID 19). Jakarta: Kementerian Pendidikan dan Kebudayaan.

Ministry of Research, Technology and Higher Education of Indonesia. 2018. Panduan Pelaksanaan Pendidikan Profesi Guru. Jakarta: Direktorat Jenderal Pembelajaran dan Kemahasiswaan.

Moore, R. L. (2020). Developing lifelong learning with heutagogy: contexts, critiques, and challenges. Distance Education, 41(3), 381-401.

Murdiyanto, T. (2020). Persepsi Peserta PPG dalam Jabatan terhadap Pelaksanaan Program PPG Hybrid Learning Bidang Studi Matematika Universitas Negeri Jakarta Tahun 2019. Jurnal riset pembelajaran matematika sekolah, 4(1), 76-84.

Peeters, A., \& Robinson, V. (2015). A teacher educator learns how to learn from mistakes: single and double-loop learning for facilitators of in-service teacher education. Studying Teacher Education, 11(3), 213-227. doi:10.1080/17425964.2015.1070728

Prihono, H. (2014). Model supervisi akademik berbasis evaluasi diri melalui MGMP sekolah untuk meningkatkan kompetensi pedagogik guru SMK di kabupaten wonogiri. Educational Management, 3(2).

Rahman, B., Abdurrahman, A., Kadaryanto, B., \& Rusminto, N. E. (2015). Teacher-based scaffolding as a teacher professional development program in Indonesia. Australian Journal of Teacher Education (Online), 40(11), 6778.

Sari, E. R. (2012). Online learning community: a case study of teacher professional development in Indonesia. Intercultural Education, 23(1), 63-72. doi:10.1080/14675986.2012.664755

Snowden, M., \& Halsall, J. (2016). Self-determined approach to learning: A social science perspective. Cogent Education, 3(1). doi:10.1080/2331186X.2016.1247608

Stephenson, J. (1998). The concept of capability and its importance in higher education. Capability and quality in higher education, 1-13. 
The World Bank. (2003). Lifelong learning in the global knowledge economy: challenges for developing countries. Washington, D.C.: World Bank. Retrieved from :https://www.researchgate.net/publication/339443123 Lifelong Learning in the Global Knowledge Eco nomy Challenges for Developing Countries

Van Woezik, T., Reuzel, R., \& Koksma, J. (2019). Exploring Open Space: A self-directed learning approach for higher education. Cogent Education, 6(1). doi:10.1080/2331186X.2019.1615766

Wehmeyer, M. L., Shogren, K. A., Toste, J. R., \& Mahal, S. (2017). Self-Determined Learning to Motivate Struggling Learners in Reading and Writing. Intervention in School and Clinic, 52(5), 295-303. doi:10.1177/1053451216676800 